Check for updates

Cite this: Nanoscale Adv., 2019, 1, 4442

\title{
Green solvent assisted synthesis of cesium bismuth halide perovskite nanocrystals and the influences of slow and fast anion exchange rates $\uparrow$
}

\begin{abstract}
Rana Faryad Ali, (D) Irene Andreu (D) and Byron D. Gates (DD*
Replacing lead in halide perovskites to address the concerns of their toxicity and stability has driven a recent surge in research toward alternative lead-free perovskite materials. Lead-free all inorganic cesium bismuth halide $\left(\mathrm{C}_{3} \mathrm{Bi}_{2} \mathrm{X}_{9}\right)$ perovskite nanocrystals have attracted attention in recent years due to the air-stability and non-toxic nature of bismuth. Herein, we demonstrate a facile sonicationassisted approach for the preparation of all-inorganic cesium bismuth iodide $\left(\mathrm{C}_{3} \mathrm{Bi}_{2} \mathrm{l}_{9}\right)$ perovskite nanocrystals (NCs) using propylene carbonate as a green, alternative solvent. The photoluminescence $(\mathrm{PL})$ spectra of the $\mathrm{Cs}_{3} \mathrm{Bi}_{2} \mathrm{X}_{9} \mathrm{NCs}$ have a peak emission that can be tuned from 410 to $550 \mathrm{~nm}$ by controlling the composition of the NCs through an anion exchange reaction using tetraalkylammonium halides as a source of halide ions. The rate of this anion exchange reaction is demonstrated to have a significant influence on the dimensions of the NCs obtained from the parent $\mathrm{Cs}_{3} \mathrm{Bi}_{2} \mathrm{l}_{9} \mathrm{NCs}$. The PL emission of these nanocrystals is predominately due to exciton recombination processes. The NCs also exhibit air-stability for at least 150 days.
\end{abstract}

Received 17th September 2019

Accepted 7th October 2019

DOI: 10.1039/c9na00586b

rsc.li/nanoscale-advances due to their hazards to human health and the environment. ${ }^{\mathbf{1 3 , 1 4}}$ The substitution of lead with relatively non-toxic metals in the perovskite crystal structure is highly desirable for the commercialization and widespread utilization of these

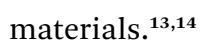

In recent years, lead-free perovskite systems have been a primary focus of research into perovskite based materials and sought after for their use in optoelectronic applications. ${ }^{\mathbf{1 5 - 1 7}}$ Several less toxic metals such as $\mathrm{Sn}, \mathrm{Ge}, \mathrm{Bi}$, and $\mathrm{Sb}$ have been explored to prepare lead-free perovskite nanomaterials. ${ }^{\mathbf{1 8 - 2 0}}$ Among lead-free perovskites, $\mathrm{Sn}$ and Ge containing perovskites are unstable due to the oxidative transformation of $\mathrm{Sn}^{2+}$ and $\mathrm{Ge}^{2+}$ to $\mathrm{Sn}^{4+}$ and $\mathrm{Ge}^{4+}$, respectively. ${ }^{21}$ For decades, Bi has been used as a nontoxic replacement for $\mathrm{Pb}$ in quantum dots and piezoelectric materials. ${ }^{21}$ Bismuth is also a promising candidate for use in perovskite based materials due to the isoelectronic structure of $\mathrm{Bi}^{3+}$ with $\mathrm{Pb}^{2+}$ and its improved chemical stability over that of $\mathrm{Sn}^{2+}$ and $\mathrm{Ge}^{2+} \cdot{ }^{20,22-26}$ Furthermore, $\mathrm{Bi}^{3+}$ and $\mathrm{Pb}^{2+}$ are adjacent in the periodic table and have very similar ionic radii, which may ease the incorporation of $\mathrm{Bi}^{3+}$ into the perovskite lattice. ${ }^{13}$ The interest in bismuth-based perovskites quickly led to the synthesis of nanocrystals (NCs), first in the form of organic/inorganic hybrid perovskites, and later also as purely inorganic cesium-based perovskites. ${ }^{27,28}$ Among these bismuth halide based perovskites, the all inorganic based cesium bismuth halide perovskite nanomaterials have exhibited a better chemical stability and have a lower density of defects than the organic based methylammonium (MA) perovskite nanomaterials..$^{\mathbf{2 0 2 2}}$ 
To the best of our knowledge, there are relatively few reports to prepare all-inorganic $\mathrm{Cs}_{3} \mathrm{Bi}_{2} \mathrm{X}_{9}$ nanocrystals through solutionphase methods. ${ }^{20,22-24}$ Many of these methods can provide good control over the size, shape, and purity of $\mathrm{Cs}_{3} \mathrm{Bi}_{2} \mathrm{X}_{9}$ nanomaterials. These methods used to prepare nanomaterials of $\mathrm{Cs}_{3} \mathrm{Bi}_{2} \mathrm{X}_{9}$ include hot-injection approaches and ligand-assisted re-precipitation (LARP) methods. The hot-injection approach uses an inert atmosphere for processing the reagents and temperatures above $100{ }^{\circ} \mathrm{C}$ to initiate the decomposition of the precursors to form the perovskite nanocrystals. ${ }^{24}$ The ligand-assisted re-precipitation process is a low cost and facile approach to synthesize perovskite NCs. ${ }^{20,29}$ In LARP, the precursors are dissolved in a "good" polar solvent (e.g., dimethyl sulfoxide or DMSO; dimethylformamide or DMF) to form a precursor solution. This dissolution step is followed by the injection of the precursor solution into a "poor" solvent, (e.g., isopropanol, toluene, or octane) to form the perovskite NCs. ${ }^{29,30}$ Similar to the hot-injection methods, the nucleation and growth stages progress rapidly and can both occur simultaneously for the LARP approaches. ${ }^{31}$ The LARP processes can result in the formation of aggregated and poorly crystallized nanostructures, and can result in relatively low reaction yields. Furthermore, some mixtures of polar and nonpolar solvents could degrade or otherwise dissolve the perovskite NCs. ${ }^{29}$ Additionally, a common polar solvent used in LARP is DMF, which is relatively toxic. $^{31}$ As an alternative, ultrasonication-based techniques provide a direct, single-step approach to preparing relatively large-scale quantities of lead halide perovskites with the ability to also tune the dimensions and shapes of the products. ${ }^{32-35}$ These ultrasonication-based approaches to prepare lead halide perovskites provide access to relatively low temperature processes, and produce a relatively less aggregated product. These approaches also enable the ability to incorporate a wide range of reagents. ${ }^{32,35}$ The sonication-based approaches have not yet been extended to the synthesis of lead-free bismuth halide perovskites.

Herein, we demonstrate a facile, green solution-phase approach for the synthesis of cesium bismuth iodide $\left(\mathrm{Cs}_{3} \mathrm{Bi}_{2} \mathrm{I}_{9}\right)$ perovskite NCs along with a characterization of their optical properties. Colloidal NCs of $\mathrm{Cs}_{3} \mathrm{Bi}_{2} \mathrm{I}_{9}$ were prepared by a simple sonicationassisted approach carried out in propylene carbonate (PC), a green solvent. This solution-phase approach to prepare $\mathrm{Cs}_{3} \mathrm{Bi}_{2} \mathrm{I}_{9}$ NCs has a number of advantages including a relatively low reaction temperature (e.g., $\sim 55^{\circ} \mathrm{C}$ ), and the manipulation of the reagents and products under an ambient atmosphere. This process prepared colloidal $\mathrm{Cs}_{3} \mathrm{Bi}_{2} \mathrm{I}_{9} \mathrm{NCs}$ with an average diameter of $9 \mathrm{~nm}$. These NCs also had a photoluminescence (PL) emission at $550 \mathrm{~nm}$ with a full-width-half-maximum (FWHM) of $65 \mathrm{~nm}$, and exhibited photostability when stored as a suspension in PC and exposed to air over a period of five months. In addition, the peak position of the PL emission of the NCs was tuned through an anion exchange reaction using either tetraoctylammonium bromide (TOA-Br) or tetrabutylammonium chloride (TBA-Cl) to adjust the halide composition of the NCs.

\section{Experimental section}

All of the chemicals were of analytical grade and were used as received without further purification. Cesium bismuth iodide
$\left(\mathrm{Cs}_{3} \mathrm{Bi}_{2} \mathrm{I}_{9}\right)$ NCs were prepared in a single step process through a sonication-assisted solution-phase approach. In brief, $60 \mathrm{mM}$ of bismuth acetate $\left[\mathrm{Bi}\left(\mathrm{OOCCH}_{3}\right)_{3},>99 \%\right.$, Sigma Aldrich] and $90 \mathrm{mM}$ of cesium iodide (CsI, >99\%, Sigma Aldrich) were prepared in $5 \mathrm{~mL}$ of propylene carbonate (PC, $>99 \%$, Sigma Aldrich). This process was followed by the addition of $0.25 \mathrm{~mL}$ oleic acid (OA, $99 \%$, Alfa Aesar) as a capping agent. The mixture was subjected to tip-assisted sonication for $15 \mathrm{~min}$ at $22 \%$ of the maximum ultrasound amplitude (Fisher Scientific Sonic Dismembrator, Model No. 500, maximum output of $500 \mathrm{~W}$ ) with intervals of $1 \mathrm{~s}$ on and $1 \mathrm{~s}$ off. During the course of the reaction, the colour of the reaction mixture changed from colorless to dark orange, indicating the formation of the $\mathrm{Cs}_{3} \mathrm{Bi}_{2} \mathrm{I}_{9}$ NCs. After completion of the reaction, any larger particles were removed from the suspension via a process of centrifugation (Model No. AccuSpin 400, Fisher Scientific) at $5000 \mathrm{rpm}$ for $5 \mathrm{~min}$ to obtain a transparent orange colored solution that contained a suspension of the NCs.

The solution containing the $\mathrm{Cs}_{3} \mathrm{Bi}_{2} \mathrm{I}_{9}$ NCs was used for the subsequent halide substitution reactions, and for studying the optical properties of these materials. Both $\mathrm{Cs}_{3} \mathrm{Bi}_{2} \mathrm{Br}_{9}$ and $\mathrm{Cs}_{3}$ $\mathrm{Bi}_{2} \mathrm{Cl}_{9} \mathrm{NCs}$ were prepared by halide substitution of the $\mathrm{Cs}_{3} \mathrm{Bi}_{2} \mathrm{I}_{9}$ NCs at ambient temperatures. In brief, a $0.03 \mathrm{M}$ (for a slower anion exchange reaction) and $0.08 \mathrm{M}$ (for a faster anion exchange reaction) solution of either tetraoctylammonium bromide (TOA-Br, 99\%, Fluka) or tetrabutylammonium chloride (TBA-Cl, 99\%, Fluka) were prepared in propylene carbonate as the source of halide to be used in the anion exchange processes. A solution of the appropriate halide species was added either relatively slowly (e.g., $1 \mu \mathrm{L}$ per $5 \mathrm{~s}$ ) or relatively fast (e.g., $10 \mu \mathrm{L}$ per $5 \mathrm{~s}$ ) to the as-prepared colloidal solution of $\mathrm{Cs}_{3} \mathrm{Bi}_{2} \mathrm{I}_{9} \mathrm{NCs}$. A series of ultraviolet (UV)-visible absorbance spectra were obtained as a function of reaction time to monitor the anion exchange processes.

For analysis of the products by powder X-ray diffraction (XRD) and Raman spectroscopy, the $\mathrm{Cs}_{3} \mathrm{Bi}_{2} \mathrm{X}_{9}$ NCs were precipitated from solution by adding chloroform to the suspension of NCs in propylene carbonate, which was followed by centrifugation of the solution at $10000 \mathrm{rpm}$ for $15 \mathrm{~min}$. The supernatant was decanted and the obtained precipitates were dried before performing these analyses.

\section{Characterization of the cesium bismuth halide $\left(\mathrm{Cs}_{3} \mathrm{Bi}_{2} \mathrm{X}_{9}\right)$ nanocrystals}

The morphology, dimensions, crystallinity, and lattice parameters of the $\mathrm{Cs}_{3} \mathrm{Bi}_{2} \mathrm{X}_{9}$ NCs were characterized using an FEI Osiris $\mathrm{X}$-FEG 8 transmission electron microscope (TEM) operated at an accelerating voltage of $200 \mathrm{kV}$. Analyses by energy dispersive Xray spectroscopy (EDX) were performed using the FEI Osiris scanning/TEM, which was equipped with a Super-X EDX system with ChemiSTEM Technology integrating the signal from four spectrometers. Samples were prepared for TEM analysis by dispersing each of the purified products in hexanes followed by drop casting $5 \mu \mathrm{L}$ of each suspension onto separate TEM grids (200 mesh copper grids coated with Formvar/carbon) purchased from Cedarlane Laboratories. Each TEM grid was dried under vacuum ( $\sim 230$ torr) for at least $8 \mathrm{~h}$ prior to analysis. 
Phase and crystallinity of each sample was also assessed by XRD analyses performed using a Rigaku R-Axis Rapid diffractometer equipped with a $3 \mathrm{~kW}$ sealed tube copper source $(\mathrm{K} \alpha$ radiation, $\lambda=0.15418 \mathrm{~nm}$ ) collimated to $0.5 \mathrm{~mm}$. Powder samples were packed into cylindrical recesses drilled into glass microscope slides (Leica $1 \mathrm{~mm}$ Surgipath Snowcoat X-tra Micro Slides) for acquiring their diffraction patterns.

Purity and phase of the products were further assessed using Raman spectroscopy techniques. Raman spectra were collected using a Renishaw inVia Raman microscope with a $50 \times$ long working distance (LWD) objective lens (Leica, $0.5 \mathrm{NA}$ ) and a $785 \mathrm{~nm}$ argon ion laser (Modu-Laser, Model No. Stellar-Pro $514 / 50$ ) set to $10 \%$ laser power with an exposure time of $30 \mathrm{~s}$. The Raman spectrometer was calibrated by collecting the Raman spectrum of a polished silicon (Si) standard with a distinct peak centered at $520 \mathrm{~cm}^{-1}$. Raman spectra were collected for each of the powdered samples, which were supported on glass slide (Leica $1 \mathrm{~mm}$ Surgipath Snowcoat X-tra Micro Slides). The spectra were acquired from 50 to $300 \mathrm{~cm}^{-1}$ using a grating with 1800 lines per $\mathrm{mm}$.

The optical absorption spectra of the $\mathrm{Cs}_{3} \mathrm{Bi}_{2} \mathrm{X}_{9}$ NCs were measured using an Agilent Technologies UV-visible spectrophotometer (Agilent 8453, Model No. G1103). For these measurements, the NCs suspended in PC were held in $1 \mathrm{~cm}$ path length poly(methyl methacrylate) cuvettes (VWR ${ }^{\mathrm{TM}}$, Catalog No. 634-8537). For the stability experiments, the NCs were stored as a suspension in PC over a period of 2 months. A series of UV-Visible spectra were recorded throughout this period of time (e.g., 4, 8, 12, 30, 60 and 150 days). Photoluminescence measurements of the $\mathrm{Cs}_{3} \mathrm{Bi}_{2} \mathrm{X}_{9}$ NCs were carried out using a Photon Technology International (PTI) Quantamaster spectrofluorometer using excitation wavelengths that matched the extinction maxima for each composition of NCs. The absolute photoluminescence quantum efficiency (PLQE) of the $\mathrm{Cs}_{3} \mathrm{Bi}_{2} \mathrm{I}_{9}$ NCs was measured using an FS5 spectrofluorometer (Edinburgh instruments) equipped with an integrating sphere (FS5 SC-30). To minimize the self-quenching effects, the absorbance of the sample was set below 0.2 at the excitation wavelength with a $10 \mathrm{~mm}$ quartz cuvette. The blank emission (e.g., from a solution of PC) was collected with the same cuvette containing only the solvent as a blank in the same spectral range used for the sample emission measurement. The absolute PLQE values were calculated using eqn S1 in ESI. $\dagger$ The timeresolved PL spectra were collected on a Horiba PTI QuantaMasterTM 400 with a DeltaFlex time-correlated single photon counting (TCSPC) lifetime measurement system equipped with a $370 \mathrm{~nm}$ excitation laser pulse. The instrument response function was measured using a non-fluorescent LUDOX ${ }^{\circledR}-50$ scatterer (50 wt\% suspension of silica beads in water, Sigma Aldrich).

\section{Results and discussion}

The $\mathrm{Cs}_{3} \mathrm{Bi}_{2} \mathrm{I}_{9}$ NCs were prepared in one-step by a solution-phase sonication process. We used PC, a green solvent, ${ }^{31}$ for the synthesis of the halide perovskite. Propylene carbonate has a relatively high boiling point (i.e., $\left.240{ }^{\circ} \mathrm{C}\right)$, and is considered to be a nonhazardous solvent. The polar nature of the PC enables the ability to readily dissolve a variety of ionic species, such as the precursors to the $\mathrm{Cs}_{3} \mathrm{Bi}_{2} \mathrm{I}_{9}$ NCs. In this method, tip-assisted sonication was used to induce the formation of $\mathrm{Cs}_{3} \mathrm{Bi}_{2} \mathrm{I}_{9} \mathrm{NCs}$ through a one-pot process directly from its molecular constituents (i.e., bismuth acetate and cesium iodide) in the presence of a surfactant, oleic acid. The formation of the $\mathrm{Cs}_{3} \mathrm{Bi}_{2} \mathrm{I}_{9} \mathrm{NCs}$ during the reaction was noted by a change in the appearance of the solution, changing from colorless to a dark orange color. Transmission electron microscopy (TEM) analysis of the assynthesized $\mathrm{Cs}_{3} \mathrm{Bi}_{2} \mathrm{I}_{9} \mathrm{NCs}$ indicated the formation of uniform and well-dispersed NCs with quasi-spherical shapes (Fig. 1a). The average diameter of these NCs was $9 \pm 2 \mathrm{~nm}$ (Fig. 1b). The atomic-scale crystallinity of the $\mathrm{Cs}_{3} \mathrm{Bi}_{2} \mathrm{I}_{9}$ nanoparticles was analyzed by high-resolution TEM (HRTEM) (Fig. 1c). A uniform lattice structure was observed throughout each of the nanocrystals. These results suggested that each nanoparticle was formed as a single crystal. The periodic fringe patterns observed by HRTEM for some of these nanocrystals had a spacing of 2.2 A. This spacing matched the inter-planar spacing for the (315) planes of $\mathrm{Cs}_{3} \mathrm{Bi}_{2} \mathrm{I}_{9}$. Composition of the $\mathrm{Cs}_{3} \mathrm{Bi}_{2} \mathrm{I}_{9}$ NCs was further confirmed by energy dispersive X-ray spectroscopy (EDX), which
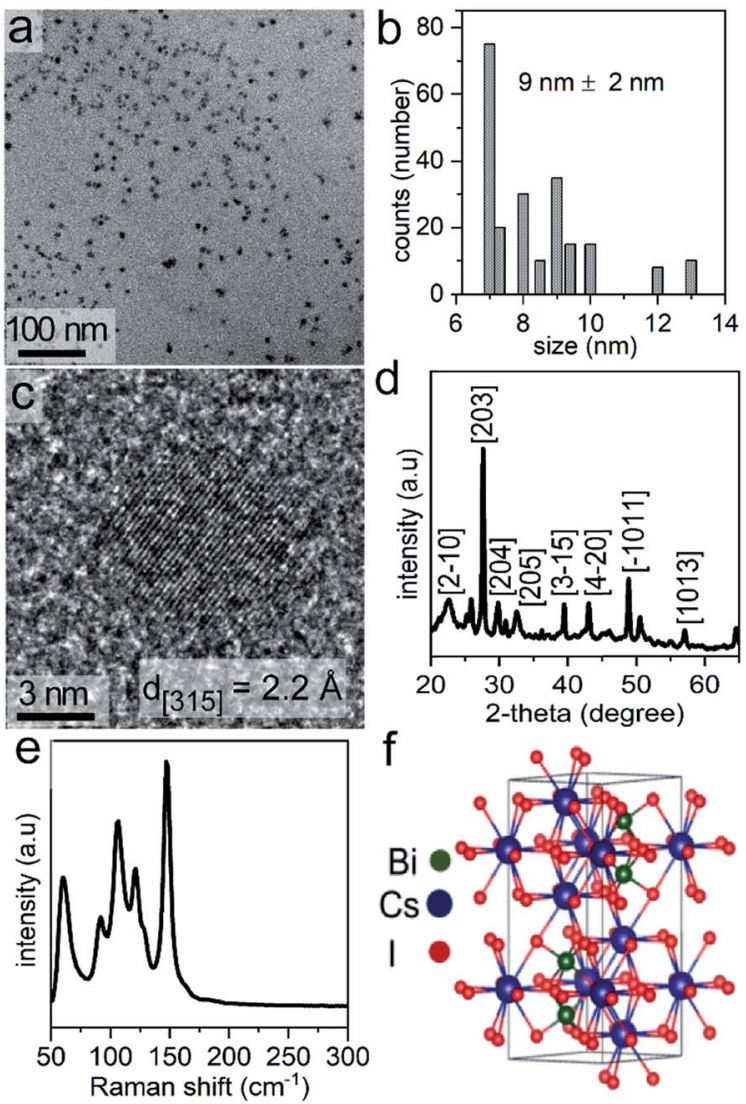

Fig. 1 Cesium bismuth iodide $\left(\left.\mathrm{Cs}_{3} \mathrm{Bi}_{2}\right|_{9}\right)$ nanocrystals (NCs) as characterized by: (a) transmission electron microscopy (TEM) imaging; (b) a histogram of their size distribution obtained from TEM analyses; (c) a high-resolution (HR) TEM analysis; (d) a powder X-ray diffraction analysis; (e) Raman spectroscopy techniques; and ( $f$ ) a model of the hexagonal crystal structure for $\mathrm{Cs}_{3} \mathrm{Bi}_{2} \mathrm{l}_{9}$. 
indicated the presence of Cs, Bi and I in the NCs (Fig. S1 in ESI $\dagger$ ).

Bismuth based perovskite NCs containing other halides (e.g., $\mathrm{Cs}_{3} \mathrm{Bi}_{2} \mathrm{Br}_{9}, \mathrm{Cs}_{3} \mathrm{Bi}_{2} \mathrm{Cl}_{9}$, and mixed halide species) were prepared through a simple process of anion exchange. Post-synthetic chemical transformations through ion-exchange reactions are a simple and versatile approach to creating new materials that are not readily accessible by other techniques, and can provide a fine control over the final composition of a material. ${ }^{36,37}$ Recently, anion exchange reactions of halide perovskites have rapidly emerged as an approach to tuning their composition and to prepare mixed halide phases. ${ }^{29,38}$ Due to the high mobility of the halide ions and the rigid nature of the cationic sub-lattice of halide perovskites, anion-exchange reactions are a versatile approach to tune the optical properties of a variety of perovskites. $^{3,29}$ There is, however, little known with regards to the effects of the rate of the anion-exchange reactions on the properties of the product, such as the optical properties and the dimensions of the resulting perovskites. ${ }^{38}$ The anion exchange process is relatively fast (e.g., several seconds) and can be achieved at ambient or lower temperatures to deliberately achieve either with a partial or complete exchange of the anions. The anion exchange reactions reported herein were conducted by suspending the NCs in propylene carbonate and adding tetraalkylammonium halides (TAA-X; $\mathrm{X}=\mathrm{Cl}^{-}$or $\mathrm{Br}^{-}$) as a source of the desired anion for the exchange. We selected tetraalkylammonium halides to facilitate the exchange of $\mathrm{I}^{-}$with either $\mathrm{Br}^{-}$or $\mathrm{Cl}^{-}$by hindering the reverse reactions. This unidirectional ion exchange process is attributed to the interactions of hard and soft acids and bases. The tetraalkylammonium cation $\left(\mathrm{TAA}^{+}\right)$with its four alkyl chains is a soft acid that prefers to bind to softer halide ions. ${ }^{38}$ Therefore, the $\mathrm{TAA}^{+}$cation prefers to associate with $\mathrm{I}^{-}$over $\mathrm{Br}^{-}$or $\mathrm{Cl}^{-}$. When reacting the $\mathrm{Cs}_{3} \mathrm{Bi}_{2} \mathrm{I}_{9}$ NCs with tetraoctylammonium bromide (TOA-Br) the $\mathrm{Br}^{-}$ readily exchanged with $\mathrm{I}^{-}$from the NCs lattice. In other words, the transformation from TOA-Br to TOA-I is favorable. The exchange for $\mathrm{I}^{-}$in $\mathrm{Cs}_{3} \mathrm{Bi}_{2} \mathrm{I}_{9}$ NCs with $\mathrm{Cl}^{-}$available from tetrabutylammonium chloride (TBA-Cl) is also feasible as the transformation from TBA-Cl to TBA-I is favorable (e.g., the $\mathrm{I}^{-}$ ions are softer than $\mathrm{Cl}^{-}$).

The dimensions of the NCs were significantly affected by the rate of the anion exchange reaction. A relatively slow anion exchange reaction (Fig. 2) used to prepare the $\mathrm{Cs}_{3} \mathrm{Bi}_{2} \mathrm{Br}_{9}$ and $\mathrm{Cs}_{3} \mathrm{Bi}_{2} \mathrm{Cl}_{9}$ NCs resulted the formation of particles with comparable dimensions to those of $\mathrm{Cs}_{3} \mathrm{Bi}_{2} \mathrm{I}_{9}$ (Fig. 3, and S2 in ESI $\dagger$ ). The TEM analyses of the $\mathrm{Cs}_{3} \mathrm{Bi}_{2} \mathrm{Br}_{9}$ NCs acquired after completing a relatively slow halide exchange process indicated that these NCs were also crystalline and maintained a quasispherical shape. The average diameter of these $\mathrm{Cs}_{3} \mathrm{Bi}_{2} \mathrm{Br}_{9} \mathrm{NCs}$ was $7 \pm 2 \mathrm{~nm}$ (Fig. S3 in ESI $\dagger$ ). The TEM analyses of the $\mathrm{Cs}_{3}{ }^{-}$ $\mathrm{Bi}_{2} \mathrm{Cl}_{9} \mathrm{NCs}$, also prepared by the relatively slow anion exchange process, revealed that these NCs were also crystalline, but that these products exhibited more irregular shapes and an increase in the polydispersity of the particles. The average diameter of these $\mathrm{Cs}_{3} \mathrm{Bi}_{2} \mathrm{Cl}_{9} \mathrm{NCs}$ was $11 \pm 5 \mathrm{~nm}$ (Fig. S3 in ESI $\dagger$ ). These variations in the shape and size of the $\mathrm{Cs}_{3} \mathrm{Bi}_{2} \mathrm{Cl}_{9} \mathrm{NCs}$ from the as-synthesized, parent $\mathrm{Cs}_{3} \mathrm{Bi}_{2} \mathrm{I}_{9}$ NCs could be attributed to the
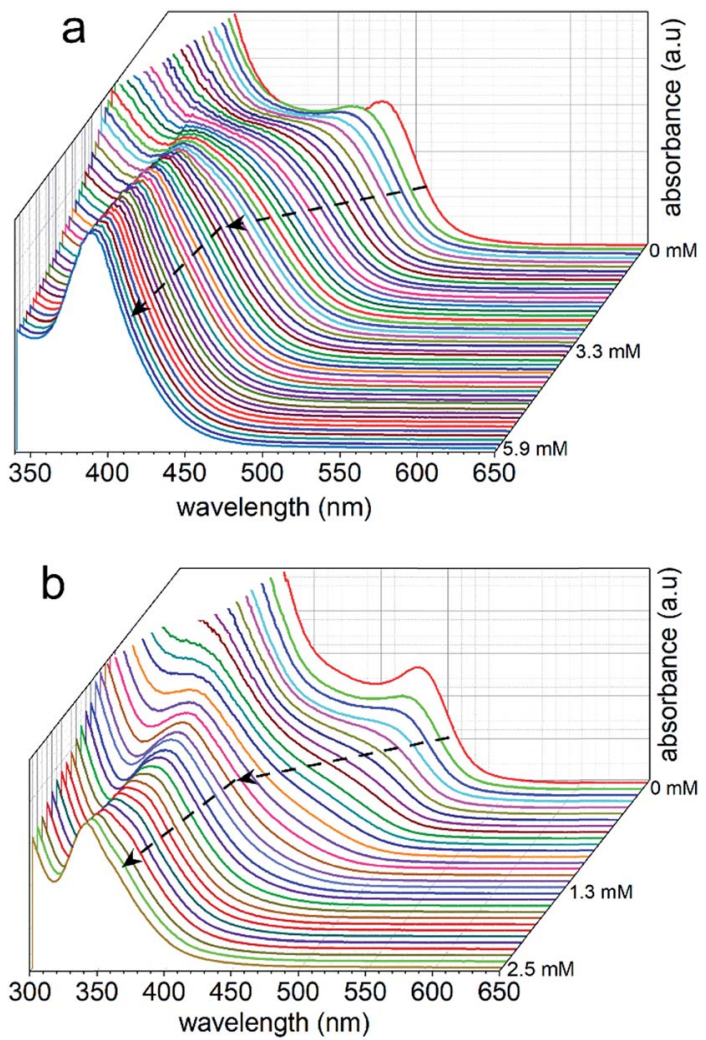

Fig. 2 Ultraviolet (UV)-visible absorption spectra acquired over the course of the reaction to monitor a relatively slow anion exchange process for the parent $\left.\mathrm{Cs}_{3} \mathrm{Bi}_{2}\right|_{9} \mathrm{NCs}$ through the formation of mixed (a) $\mathrm{l} / \mathrm{Br}$ and (b) l/Cl nanocrystals by the substitution of $\mathrm{I}^{-}$with $\mathrm{Br}^{-}$and $\mathrm{Cl}^{-}$, respectively. The addition of tetraalkylammonium halides in an increasing concentration (as noted next to the spectra) were used to initiate the anion exchange reaction, which resulted in a blue-shift in the absorption spectra. The absorption spectra quickly stabilized, exhibiting no further shifts with subsequent additions of either $\mathrm{Br}^{-}$or $\mathrm{Cl}^{-}$anions to the solution. This stabilization of the spectra indicated a completion of the anion exchange process.

larger difference in radii of the $\mathrm{Cl}^{-}$and $\mathrm{I}^{-}$ions. The replacement of the $\mathrm{I}^{-}$by $\mathrm{Cl}^{-}$within the crystalline lattice likely disrupts the structure of these materials..$^{3940}$ This ion exchange process could lead to a partial dissolution, reshaping, and aggregation of the NCs. Increasing the relative rate of the anion exchange reactions (Fig. S4 and S5 in ESI $\dagger$ ) resulted in an increase in the average diameter and polydispersity of the $\mathrm{Cs}_{3} \mathrm{Bi}_{2} \mathrm{Br}_{9}$ and $\mathrm{Cs}_{3}$ $\mathrm{Bi}_{2} \mathrm{Cl}_{9}$ NCs. These $\mathrm{Cs}_{3} \mathrm{Bi}_{2} \mathrm{Br}_{9}$ and $\mathrm{Cs}_{3} \mathrm{Bi}_{2} \mathrm{Cl}_{9}$ NCs had average dimensions of $12 \pm 4 \mathrm{~nm}$ and $22 \pm 6 \mathrm{~nm}$, respectively (Fig. 4). A number of smaller particles with average dimensions of $\sim 4 \mathrm{~nm}$ were also observed along with these larger $\mathrm{Cs}_{3} \mathrm{Bi}_{2} \mathrm{Cl}_{9} \mathrm{NCs}$, which may result from a partial dissolution of the NCs during the anion exchange process. It is possible that the overall increase in size of the NCs observed during this fast ion exchange process could be attributed to an initial dissolution of the $\mathrm{Cs}_{3} \mathrm{Bi}_{2} \mathrm{I}_{9} \mathrm{NCs}$, forming smaller nuclei. Subsequent nucleation and aggregative growth of these nuclei would result in the formation of the larger $\mathrm{Cs}_{3} \mathrm{Bi}_{2} \mathrm{Cl}_{9} \mathrm{NCs}^{41,42}$ During aggregative growth, the deposition of the nuclei on the higher energy facets 

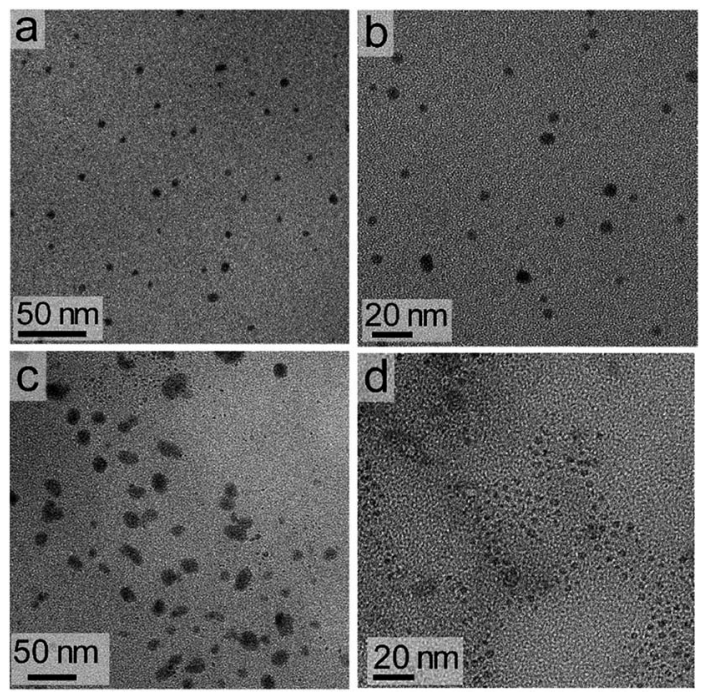

Fig. 3 Transmission electron microscopy (TEM) analyses of the nanocrystals (NCs) after a relatively slow anion exchange reaction: (a and b) cesium bismuth bromide $\left(\mathrm{Cs}_{3} \mathrm{Bi}_{2} \mathrm{Br}_{9}\right)$ nanocrystals; and ( $\mathrm{c}$ and d) cesium bismuth chloride $\left(\mathrm{Cs}_{3} \mathrm{Bi}_{2} \mathrm{Cl}_{9}\right)$ nanocrystals. The larger, dark regions observed in (c) are associated with assemblies of smaller nanoparticles as shown in (d).
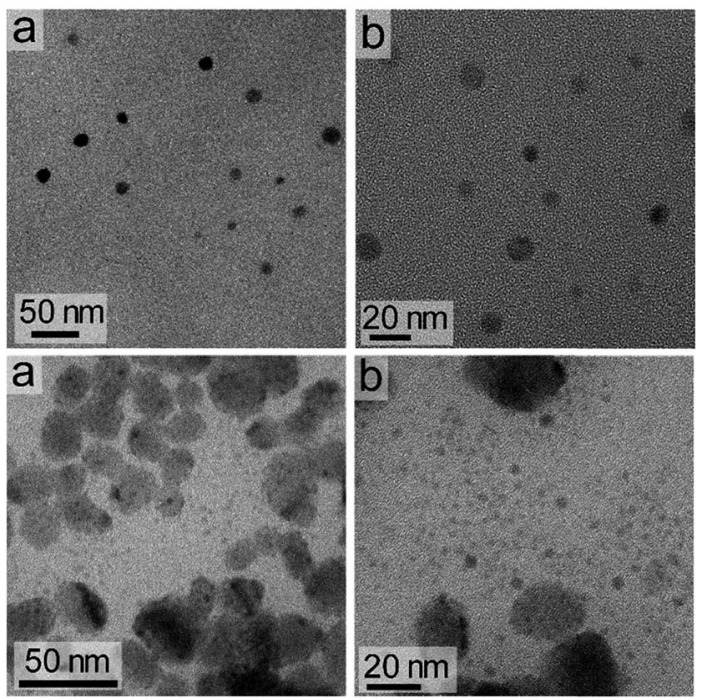

Fig. 4 Transmission electron microscopy (TEM) analyses of the nanocrystals (NCs) after a relatively fast ion exchange reaction: (a and b) cesium bismuth bromide $\left(\mathrm{Cs}_{3} \mathrm{Bi}_{2} \mathrm{Br}_{9}\right)$ nanocrystals; and ( $\mathrm{c}$ and $\mathrm{d}$ ) cesium bismuth chloride $\left(\mathrm{C}_{3} \mathrm{Bi}_{2} \mathrm{Cl}_{9}\right)$ nanocrystals. The average dimensions of the $\mathrm{Cs}_{3} \mathrm{Bi}_{2} \mathrm{Br}_{9}$ and $\mathrm{Cs}_{3} \mathrm{Bi}_{2} \mathrm{Cl}_{9} \mathrm{NCs}$ increased to $\sim 12 \mathrm{~nm}$ and $\sim 22 \mathrm{~nm}$, respectively.

also lead to a reshaping and an increase in the dimensions of the NCs. ${ }^{43}$ The ion-exchange process begins from the edges of the particles and proceeds toward their core. ${ }^{44,45}$ These ion exchange reactions have a small activation energy as they are thought to proceed through a kick-out mechanism, and that the rate-determining step is not the rate of diffusion but instead the rate of the ion exchange. ${ }^{44-46}$ These faster rates for the ion exchange reaction result in a significant mass transport between the inner core and exterior of the particles, which could result in a dissolution or partial deterioration of their structure. $^{44}$

Powder X-ray diffraction (XRD) patterns were obtained for the as-synthesized $\mathrm{Cs}_{3} \mathrm{Bi}_{2} \mathrm{I}_{9} \mathrm{NCs}$ (Fig. 1d, and $\mathrm{S} 6$ in ESI $\dagger$ ), as well as for the $\mathrm{Cs}_{3} \mathrm{Bi}_{2} \mathrm{Cl}_{9}$ and $\mathrm{Cs}_{3} \mathrm{Bi}_{2} \mathrm{Br}_{9}$ NCs resulting from the relatively slow halide exchange reactions (Fig. S7 in ESI†). The major peaks in the XRD patterns of the $\mathrm{Cs}_{3} \mathrm{Bi}_{2} \mathrm{I}_{9} \mathrm{NCs}$ matched the hexagonal crystal structure expected for $\mathrm{Cs}_{3} \mathrm{Bi}_{2} \mathrm{I}_{9}$ (space group $P 6_{3} / m m c$, ICSD No. 410726). The $\mathrm{Cs}_{3} \mathrm{Bi}_{2} \mathrm{Cl}_{9} \mathrm{NCs}$ and $\mathrm{Cs}_{3} \mathrm{Bi}_{2} \mathrm{Br}_{9}$ NCs were also crystalline, and had major diffraction peaks similar to the XRD profiles to those previously reported for bulk crystals of $\mathrm{Cs}_{3} \mathrm{Bi}_{2} \mathrm{Cl}_{9}$ and $\mathrm{Cs}_{3} \mathrm{Bi}_{2} \mathrm{Br}_{9}$. In comparison to these bulk single-crystals, the diffraction peaks for the samples of NCs were significantly broader, which can be attributed to the nanoscale dimensions of the colloidal NCs. ${ }^{47,48}$ Differences in the peak positions for some of the peaks observed in the XRD plots for the NCs relative to those for the ICSD standards, as seen in Fig. S6 and S7 in ESI, $\uparrow$ are attributed to the intrinsic structural properties of the perovskite NCs. These intrinsic properties include unit cell distortions and other structural strains that result from the small dimensions of the nanocrystals, and the preferred directions of crystal growth for the nanocrystals relative to the bulk crystals used as reference materials ${ }^{49}$ Further distortions could result from the processes of precipitating the NCs from solution and drying them in preparation for the XRD analyses. These induced transformations of the perovskite NCs may also lead to the formation of polycrystalline and/or aggregated products. ${ }^{50}$ Similar interferences and environmental influences on the reflections observed in the XRD plots have been observed in many previous reports for perovskite-based nanomaterials. ${ }^{20,21,23,24}$ The relative intensities of some reflections are also distinct from those observed in the bulk crystals, which is due to changes in the relative growth directions of the lattices in the form of the NCs.

Phase, crystallinity, and purity of the products were further analyzed by Raman spectroscopy techniques. Raman spectra were recorded from 50 to $300 \mathrm{~cm}^{-1}$. No peaks were observed above $300 \mathrm{~cm}^{-1}$. Raman spectra of $\mathrm{Cs}_{3} \mathrm{Bi}_{2} \mathrm{I}_{9}$ contain two major peaks above $110 \mathrm{~cm}^{-1}$, along with three strong modes between 50 and $110 \mathrm{~cm}^{-1}$ (Fig. 1e). The Raman bands associated with the $\mathrm{Cs}_{3} \mathrm{Bi}_{2} \mathrm{I}_{9}$ NCs further indicated the formation of a crystalline product. ${ }^{51}$ The Raman spectra of the $\mathrm{Cs}_{3} \mathrm{Bi}_{2} \mathrm{Cl}_{9}$ and $\mathrm{Cs}_{3} \mathrm{Bi}_{2} \mathrm{Br}_{9}$ NCs also indicated the formation of crystalline products (Fig. S8 in ESI $\dagger$ ). ${ }^{52}$ The observed vibrational modes of the $\mathrm{Cs}_{3} \mathrm{Bi}_{2} \mathrm{I}_{9}$ lattice (space group $\mathrm{PG}_{3} / \mathrm{mmc}$ ) are derived mainly from the vibrations of the $\left[\mathrm{Bi}_{2} \mathrm{I}_{9}\right]^{3-}$ anion. The crystal structure consists of molecular $\left[\mathrm{Bi}_{2} \mathrm{I}_{9}\right]^{3-}$ anions bound together by three $\mathrm{Cs}^{+}$cations per unit cell (Fig. 1f). The dominant vibrations in the crystalline lattice of $\mathrm{Cs}_{3} \mathrm{Bi}_{2} \mathrm{I}_{9}$ arise from the strong bonds of the $\left[\mathrm{Bi}_{2} \mathrm{I}_{9}\right]^{3-}$ sub-unit and the weaker modes arise from the ionic interactions of that sub-unit with the bridging $\mathrm{Cs}^{+}$cations (Table S1 in ESI $\dagger$ ). ${ }^{51,53,54}$ The peak positions within the Raman spectra of the $\mathrm{Cs}_{3} \mathrm{Bi}_{2} \mathrm{Br}_{9}$ and $\mathrm{Cs}_{3} \mathrm{Bi}_{2} \mathrm{Cl}_{9}$ NCs were also in agreement with the data previously reported for larger $\mathrm{Cs}_{3} \mathrm{Bi}_{2} \mathrm{Br}_{9}$ and $\mathrm{Cs}_{3} \mathrm{Bi}_{2} \mathrm{Cl}_{9}$ crystals. ${ }^{52}$ 
The optical properties of the $\mathrm{Cs}_{3} \mathrm{Bi}_{2} \mathrm{X}_{9}$ NCs were investigated as colloidal suspensions under ambient conditions to evaluate their excitation and PL response. The $\mathrm{Cs}_{3} \mathrm{Bi}_{2} \mathrm{I}_{9}$ NCs had an excitation peak maximum centered at $\sim 485 \mathrm{~nm}$ and an associated emission peak at $550 \mathrm{~nm}(2.25 \mathrm{eV})$ with an FWHM of $65 \mathrm{~nm}$. The PLQE of the $\mathrm{Cs}_{3} \mathrm{Bi}_{2} \mathrm{I}_{9}$ NCs was measured using a fluorescence spectrometer equipped with an integrating sphere, which yielded a PLQE value of $\sim 0.3 \%$. The absolute PLQE value of these $\mathrm{Cs}_{3} \mathrm{Bi}_{2} \mathrm{I}_{9} \mathrm{NCs}$ is higher than those previously reported in the literature for $\mathrm{Cs}_{3} \mathrm{Bi}_{2} \mathrm{I}_{9}$ NCs prepared by other methods. ${ }^{22,55}$ The PL spectra of the $\mathrm{Cs}_{3} \mathrm{Bi}_{2} \mathrm{X}_{9}$ NCs were finely tuned from 550 to $410 \mathrm{~nm}$ by varying their anion composition ( $\mathrm{X}=\mathrm{Br}, \mathrm{Cl}$, and $\mathrm{I}$ ). The source of halide species for these anion exchange reactions were the tetraalkylammonium halides, which were highly soluble in PC. The extent of the halide exchange reaction was assessed by monitoring changes to the optical absorption spectra of the NCs (e.g., Fig. 2). After the anion exchange with $\mathrm{Br}^{-}$or $\mathrm{Cl}^{-}$ions, the excitation peak of the NCs exhibited a blue-shift (Fig. 5 and Table S2 in ESI $\dagger$ ). This blue-shift in the absorption spectra was associated with an increase in the bandgap energy of the NCs after the anion exchange. The $\mathrm{Cs}_{3} \mathrm{Bi}_{2} \mathrm{Cl}_{9} \mathrm{NCs}$ and $\mathrm{Cs}_{3} \mathrm{Bi}_{2} \mathrm{Br}_{9}$ NCs exhibited absorption peaks at $337 \mathrm{~nm}$ and $385 \mathrm{~nm}$, and their

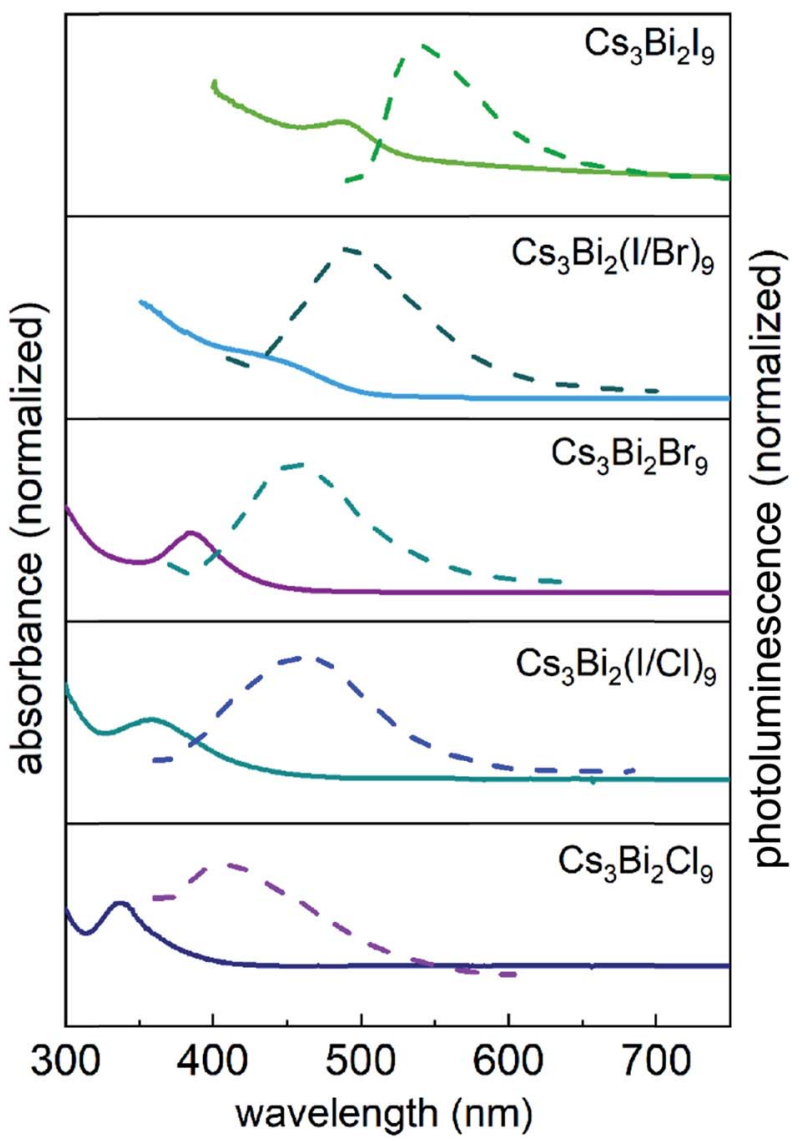

Fig. 5 Absorption (solid) and photoluminescence (dashed) spectra of the perovskite $\mathrm{Cs}_{3} \mathrm{Bi}_{2} l_{9} \mathrm{NCs}$, as well as NCs containing $\mathrm{Br}^{-}$and $\mathrm{Cl}^{-}$ prepared by the substitution of $\mathrm{I}^{-}$with $\mathrm{Br}^{-}$(2nd and 3rd panels from the top) and $\mathrm{Cl}^{-}$(4th and 5th panels from the top). corresponding PL emission peaks were centered at $410 \mathrm{~nm}(3.02$ $\mathrm{eV})$ and $460 \mathrm{~nm}(2.70 \mathrm{eV})$, respectively (Fig. 5). The bandgaps of the $\mathrm{Cs}_{3} \mathrm{Bi}_{2} \mathrm{I}_{9}, \mathrm{Cs}_{3} \mathrm{Bi}_{2} \mathrm{Cl}_{9}$, and $\mathrm{Cs}_{3} \mathrm{Bi}_{2} \mathrm{Br}_{9}$ NCs were each assessed to determine if they contained either direct or indirect transitions through the use of Tauc plots. ${ }^{56}$ These plots were obtained by replotting the absorption spectra as $(\alpha h \nu)^{1 / n}$ versus $h \nu$. The parameter $n$ denotes the type of electronic transition, with a value of $1 / 2$ used for direct transitions. ${ }^{55}$ The bandgaps associated with direct electronic transitions, as determined from these Tauc plots, were $2.33 \mathrm{eV}, 2.81 \mathrm{eV}$ and $3.37 \mathrm{eV}$ for the $\mathrm{Cs}_{3} \mathrm{Bi}_{2} \mathrm{I}_{9} \mathrm{NCs}, \mathrm{Cs}_{3} \mathrm{Bi}_{2} \mathrm{Br}_{9} \mathrm{NCs}$, and $\mathrm{Cs}_{3} \mathrm{Bi}_{2} \mathrm{Cl}_{9}$ NCs, respectively (Fig. S9 in ESI $\dagger$ ). Peak PL emissions for the $\mathrm{Cs}_{3} \mathrm{Bi}_{2} \mathrm{I}_{9}$ NCs and $\mathrm{Cs}_{3} \mathrm{Bi}_{2} \mathrm{Br}_{9}$ NCs were in close agreement to the bandgaps predicted for direct electronic transitions through the Tauc plots. These results do not rule out contributions from an indirect electronic transitions. ${ }^{55}$ The peak PL emission for the $\mathrm{Cs}_{3} \mathrm{Bi}_{2} \mathrm{Cl}_{9}$ NCs were, however, not as closely matched with the bandgaps predicted for a direct electronic transition. This mismatch could be attributed to defects resulting from the partial dissolution and aggregation of these NCs during the anion exchange of $\mathrm{I}^{-}$with $\mathrm{Cl}^{-}$, as well as the polydispersity of this product (Fig. S3 in ESI $\dagger$ ).

Time-resolved PL spectra were acquired using timecorrelated single photon counting (TCSPC) to investigate the dynamics of exciton recombination associated with the NCs (Fig. 6, and S10 in ESI $\dagger$ ). The PL decay of the $\mathrm{Cs}_{3} \mathrm{Bi}_{2} \mathrm{I}_{9}$ NCs was fit with a biexponential decay function composed of a short-lived PL lifetime $\left(\tau_{1}\right)$ of 0.92 ns and a long-lived PL lifetime $\left(\tau_{2}\right)$ of 5.3 ns (Fig. S11 in ESI $\dagger$ ). Similar lifetimes were observed for the $\mathrm{Cs}_{3} \mathrm{Bi}_{2} \mathrm{Br}_{9}$ and $\mathrm{Cs}_{3} \mathrm{Bi}_{2} \mathrm{Cl}_{9} \mathrm{NCs}$. Each of the NCs exhibited a larger contribution from the short-lived PL decay processes over the long-lived PL decay processes (Table S3 in ESI $\dagger$ ). Previous studies suggest that the processes associated with the shortlived lifetime can be attributed to direct electronic transitions within the NCs. In contrast, the long-lived component can be attributed to indirect electronic transitions, such as through recombination events at surface defects. ${ }^{55,57}$ The fluorescence decay associated with the $\mathrm{Cs}_{3} \mathrm{Bi}_{2} \mathrm{X}_{9}$ NCs is likely governed

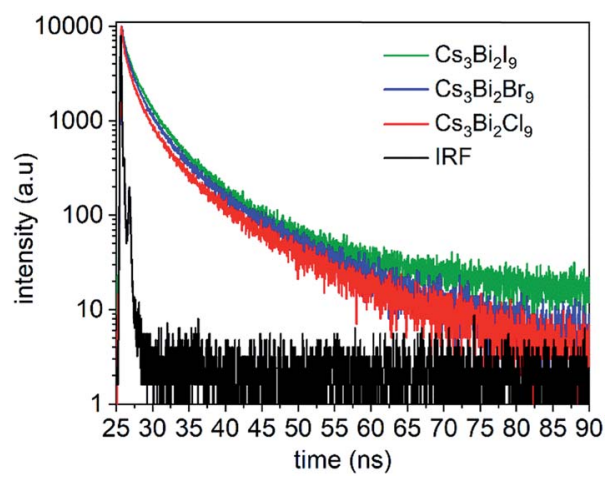

Fig. 6 Time-resolved PL spectra for $\mathrm{Cs}_{3} \mathrm{Bi}_{2} \mathrm{l}_{9} \mathrm{NCs}$ (green), $\mathrm{Cs}_{3} \mathrm{Bi}_{2} \mathrm{Br}_{9}$ $\mathrm{NCs}$ (blue), and $\mathrm{Cs}_{3} \mathrm{Bi}_{2} \mathrm{Cl}_{9} \mathrm{NCs}$ (red) as measured by time-correlated single photon counting (TCSPC) using an excitation wavelength of $370 \mathrm{~nm}$. The instrument response function (IRF) of the TCSPC set-up was measured using a non-fluorescent scatterer, LUDOX®-50. 
predominantly by exciton recombination within the $\mathrm{NCs}^{22,58}$ The $\mathrm{Cs}_{3} \mathrm{Bi}_{2} \mathrm{I}_{9}$ NCs were also studied over a period of 150 days while stored under ambient conditions to assess the stability of their optical properties. A small blue-shift $(\sim 8 \mathrm{~nm})$ and slight peak broadening $(\sim 3 \mathrm{~nm})$ were observed in the UV-Visible absorbance spectra of the nanocrystals over the course of the five months of storage (Fig. S14 in ESI $\dagger$ ). This indicated that the $\mathrm{Cs}_{3} \mathrm{Bi}_{2} \mathrm{I}_{9}$ NCs exhibited stable optical properties when stored in air as no significant changes were observed to their absorption spectra over this period of time. A slight blue-shift $(\sim 25 \mathrm{~nm})$ was observed in their PL spectra along with a similar FWHM following the 150 days of exposure to air, which indicated the relative stability of the optical properties of these NCs (Fig. S15 in $\mathrm{ESI}_{\dagger}^{\dagger}$ ).

\section{Conclusions}

In summary, we have demonstrated a solution-phase route to prepare single-crystalline $\mathrm{Cs}_{3} \mathrm{Bi}_{2} \mathrm{I}_{9}$ NCs via a facile sonicationassisted method. This single-step process uses propylene carbonate as a green solvent for the synthesis. The PL spectra of the perovskite $\mathrm{Cs}_{3} \mathrm{Bi}_{2} \mathrm{X}_{9}$ NCs were tuned from 410 to $550 \mathrm{~nm}$ by controlling their composition through an anion exchange process carried out at room temperature using tetraalkylammonium halides (TAA-X) as a source of halide ions ( $\mathrm{X}=\mathrm{Br}^{-}$ or $\mathrm{Cl}^{-}$). Controlling the rates of the anion exchange process had a significant influence on the quality of the products. For example, following a relatively slow anion exchange reaction the dimensions of the $\mathrm{Cs}_{3} \mathrm{Bi}_{2} \mathrm{Br}_{9}$ NCs and $\mathrm{Cs}_{3} \mathrm{Bi}_{2} \mathrm{Cl}_{9}$ NCs were comparable to those of the parent $\mathrm{Cs}_{3} \mathrm{Bi}_{2} \mathrm{I}_{9}$ NCs. A faster anion exchange reaction yielded NCs of $\mathrm{Cs}_{3} \mathrm{Bi}_{2} \mathrm{Br}_{9}$ and $\mathrm{Cs}_{3} \mathrm{Bi}_{2} \mathrm{Cl}_{9}$ with an increase in the relative dimensions of these products and an increase in their polydispersity. Time-resolved PL measurements indicated that the fluorescence decay associated with the NCs proceeds predominately through an exciton recombination within the NCs. The $\mathrm{Cs}_{3} \mathrm{Bi}_{2} \mathrm{I}_{9}$ NCs were also air stable for over 150 days with a slight blue-shift of their absorbance and PL properties.

\section{Conflicts of interest}

There are no conflicts to declare.

\section{Acknowledgements}

This work was supported in part by the Natural Sciences and Engineering Research Council (NSERC) of Canada (Discovery Grant No. 1077758), and through the Collaborative Health Research Projects (CHRP) Partnership Program supported in part by the Canadian Institutes of Health Research (Grant No. 134742) and the Natural Science Engineering Research Council of Canada (Grant No. CHRP 462260), the Canada Research Chairs Program (B. D. Gates, Grant No. 950-215846), and CMC Microsystems (MNT Grants No. 6345 and No. 5954). This work made use of 4D LABS (http://www.4dlabs.com) and the Center for Soft Materials shared facilities supported by the Canada Foundation for Innovation (CFI), British Columbia Knowledge
Development Fund (BCKDF), Western Economic Diversification Canada, and Simon Fraser University. We also thank Dr Saeid Kamal (4D LABS), Dr Ryan Roberts, and Prof. Daniel Leznoff for discussions and assistance with acquiring the fluorescence lifetimes and PLQE data for the samples described herein.

\section{References}

1 S.-T. Ha, R. Su, J. Xing, Q. Zhang and Q. Xiong, Chem. Sci., 2017, 8, 2522-2536.

2 W. Zhang, G. E. Eperon and H. J. Snaith, Nat. Energy, 2016, 1, 16048.

3 Q. A. Akkerman, G. Rainò, M. V Kovalenko and L. Manna, Nat. Mater., 2018, 17, 394-405.

4 S. Yakunin, L. Protesescu, F. Krieg, M. I. Bodnarchuk, G. Nedelcu, M. Humer, G. De Luca, M. Fiebig, W. Heiss and M. V Kovalenko, Nat. Commun., 2015, 6, 8056.

5 S. De Wolf, J. Holovsky, S.-J. Moon, P. Löper, B. Niesen, M. Ledinsky, F.-J. Haug, J.-H. Yum and C. Ballif, J. Phys. Chem. Lett., 2014, 5, 1035-1039.

6 A. R. Srimath Kandada and A. Petrozza, Acc. Chem. Res., 2016, 49, 536-544.

7 C. C. Stoumpos and M. G. Kanatzidis, Acc. Chem. Res., 2015, 48, 2791-2802.

8 Y. Wang and H. Sun, Small Methods, 2018, 2, 1700252.

9 H. Huang, L. Polavarapu, J. A. Sichert, A. S. Susha, A. S. Urban and A. L. Rogach, NPG Asia Mater., 2016, 8, e328. 10 A. Walsh, J. Phys. Chem. C, 2015, 119, 5755-5760.

11 Q. Zhang and Y. Yin, ACS Cent. Sci., 2018, 6, 668-679.

12 M. V Kovalenko, L. Protesescu and M. I. Bodnarchuk, Science, 2017, 358, 745-750.

13 Z. Shi, J. Guo, Y. Chen, Q. Li, Y. Pan, H. Zhang, Y. Xia and W. Huang, Adv. Mater., 2017, 29, 1605005.

14 L. Liang and P. Gao, Adv. Sci., 2018, 5, 1700331.

15 Z. Xiao, Z. Song and Y. Yan, Adv. Mater., 2019, 1803792.

16 X. Wang, T. Zhang, Y. Lou and Y. Zhao, Mater. Chem. Front., 2019, 3, 365-375.

17 W. Ning and F. Gao, Adv. Mater., 2019, 1900326.

18 D. S. Dolzhnikov, C. Wang, Y. Xu, M. G. Kanatzidis and E. A. Weiss, Chem. Mater., 2017, 29, 7901-7907.

19 J. Zhang, Y. Yang, H. Deng, U. Farooq, X. Yang, J. Khan, J. Tang and H. Song, ACS Nano, 2017, 11, 9294-9302.

20 B. Yang, J. Chen, F. Hong, X. Mao, K. Zheng, S. Yang, Y. Li, T. Pullerits, W. Deng and K. Han, Angew. Chem., 2017, 129, 12645-12649.

21 M. Leng, Y. Yang, K. Zeng, Z. Chen, Z. Tan, S. Li, J. Li, B. Xu, D. Li and M. P. Hautzinger, Adv. Funct. Mater., 2018, 28, 1704446.

22 M. Leng, Z. Chen, Y. Yang, Z. Li, K. Zeng, K. Li, G. Niu, Y. He, Q. Zhou and J. Tang, Angew. Chem., Int. Ed., 2016, 55, 1501215016.

23 Y. Lou, M. Fang, J. Chen and Y. Zhao, Chem. Commun., 2018, 54, 3779-3782.

24 R. D. Nelson, K. Santra, Y. Wang, A. Hadi, J. W. Petrich and M. G. Panthani, Chem. Commun., 2018, 54, 3640-3643.

25 B. Park, B. Philippe, X. Zhang, H. Rensmo, G. Boschloo and E. M. J. Johansson, Adv. Mater., 2015, 27, 6806-6813. 
26 J. Pal, A. Bhunia, S. Chakraborty, S. Manna, S. Das, A. Dewan, S. Datta and A. Nag, J. Phys. Chem. C, 2018, 122, 1064310649.

27 L. Zhang, K. Wang and B. Zou, ChemSusChem, 2019, 12, 1612-1630.

28 V. K. Ravi, N. Singhal and A. Nag, J. Mater. Chem. A, 2018, 6, 21666-21675.

29 J. Shamsi, A. S. Urban, M. Imran, L. De Trizio and L. Manna, Chem. Rev., 2019, 119(5), 3296-3348.

30 K. Hills-Kimball, Y. Nagaoka, C. Cao, E. Chaykovsky and O. Chen, J. Mater. Chem. C, 2017, 5, 5680-5684.

31 K. L. Gardner, J. G. Tait, T. Merckx, W. Qiu, U. W. Paetzold, L. Kootstra, M. Jaysankar, R. Gehlhaar, D. Cheyns and P. Heremans, Adv. Energy Mater., 2016, 6, 1600386.

32 Y. Tong, E. Bladt, M. F. Aygüler, A. Manzi, K. Milowska, V. A. Hintermayr, P. Docampo, S. Bals, A. Urban, P. Lakshminarayana and J. Feldmann, Angew. Chem., Int. Ed., 2016, 55, 13887-13892.

33 D. M. Jang, D. H. Kim, K. Park, J. Park, J. W. Lee and J. K. Song, J. Mater. Chem. C, 2016, 4, 10625-10629.

34 Y. Tong, B. J. Bohn, E. Bladt, K. Wang, P. Müller-Buschbaum, S. Bals, A. S. Urban, L. Polavarapu and J. Feldmann, Angew. Chem., Int. Ed., 2017, 56, 13887-13892.

35 H. Huang, Q. Xue, B. Chen, Y. Xiong, J. Schneider, C. Zhi, H. Zhong and A. L. Rogach, Angew. Chem., 2017, 129, 9699-9704.

36 H. Li, M. Zanella, A. Genovese, M. Povia, A. Falqui, C. Giannini and L. Manna, Nano Lett., 2011, 11, 4964-4970.

37 D. H. Son, S. M. Hughes, Y. Yin and A. Paul Alivisatos, Science, 2004, 306, 1009-1012.

38 Q. A. Akkerman, V. D'Innocenzo, S. Accornero, A. Scarpellini, A. Petrozza, M. Prato and L. Manna, J. Am. Chem. Soc., 2015, 137, 10276-10281.

39 R. Agarwal, N. M. Krook, M.-L. Ren, L. Z. Tan, W. Liu, A. M. Rappe and R. Agarwal, Nano Lett., 2018, 18, 1620-1627.

40 S. Gupta, S. V Kershaw and A. L. Rogach, Adv. Mater., 2013, 25, 6923-6944.

41 B. J. Beberwyck and A. P. Alivisatos, J. Am. Chem. Soc., 2012, 134, 19977-19980.
42 O. Ramirez, P. Ramasamy, Y. Chan Choi and J.-S. Lee, Chem. Mater., 2018, 31, 268-276.

43 F. Wang, V. N. Richards, S. P. Shields and W. E. Buhro, Chem. Mater., 2013, 26, 5-21.

44 L. De Trizio and L. Manna, Chem. Rev., 2016, 116, 1085210887.

45 Z. Fan, L.-C. Lin, W. Buijs, T. J. H. Vlugt and M. A. Van Huis, Nat. Commun., 2016, 7, 11503.

46 V. Lesnyak, R. Brescia, G. C. Messina and L. Manna, J. Am. Chem. Soc., 2015, 137, 9315-9323.

47 P. Scardi, M. Leoni and K. R. Beyerlein, Z. Kristallogr. - Cryst. Mater., 2011, 226, 924-933.

48 A. V Vorontsov and S. V Tsybulya, Ind. Eng. Chem. Res., 2018, 57, 2526-2536.

49 C. F. Holder and R. E. Schaak, ACS Nano, 2019, 13, 73597365.

50 E. Fanizza, F. Cascella, D. Altamura, C. Giannini, A. Panniello, L. Triggiani, F. Panzarea, N. Depalo, R. Grisorio and G. P. Suranna, Nano Res., 2019, 12, 11551166.

51 K. M. McCall, C. C. Stoumpos, S. S. Kostina, M. G. Kanatzidis and B. W. Wessels, Chem. Mater., 2017, 29, 4129-4145.

52 G. Bator, J. Baran, R. Jakubas and M. Karbowiak, Vib. Spectrosc., 1998, 16, 11-20.

53 O. V Vakulenko, V. O. Gubanov, S. V Kun, F. V Motsnyi, E. Y. Peresh and V. A. Terekhov, in Optical Diagnostics of Materials and Devices for Opto-, Micro-, and Quantum Electronics, 1997, vol. 3359, pp. 351-355.

54 A. Nila, M. Baibarac, A. Matea, R. Mitran and I. Baltog, Phys. Status Solidi, 2017, 254, 1552805.

55 Y. Zhang, J. Yin, M. R. Parida, G. H. Ahmed, J. Pan, O. M. Bakr, J.-L. Brédas and O. F. Mohammed, J. Phys. Chem. Lett., 2017, 8, 3173-3177.

56 J. Tauc, R. Grigorovici and A. Vancu, Phys. Status Solidi, 1966, 15, 627-637.

57 V. Sarritzu, N. Sestu, D. Marongiu, X. Chang, Q. Wang, S. Masi, S. Colella, A. Rizzo, A. Gocalinska and E. Pelucchi, Adv. Opt. Mater., 2018, 1701254.

58 G. D. Scholes and G. Rumbles, Nat. Mater., 2006, 5, 683-696. 